\title{
Fluorescence Photoactivation by Intermolecular Proton Transfer
}

\author{
Subramani Swaminathan, ${ }^{\ddagger}$ Marco Petriella, ${ }^{\S}$ Erhan Deniz, ${ }^{\ddagger}$ Janet Cusido, ${ }^{\ddagger}$ James D. Baker, ${ }^{\dagger}$ \\ Mariano L. Bossi, ${ }^{*, \S}$ and Françisco M. Raymo*, \\ Laboratory for Molecular Photonics, Departments of ${ }^{\dagger}$ Biology and ${ }^{\ddagger}$ Chemistry, University of Miami, 1301 Memorial Drive, Coral \\ Gables, Florida 33146-0431, United States \\ ${ }^{\S}$ INQUIMAE, Facultad de Ciencias Exactas y Naturales, Universidad de Buenos Aires, Pabellón 2, Ciudad Universitaria, 1428 Buenos \\ Aires, Argentina
}

Supporting Information

ABSTRACT: We designed a strategy to activate fluorescence under the influence of optical stimulations based on the intermolecular transfer of protons. Specifically, the illumination of a 2-nitrobenzyl derivative at an activating wavelength is accompanied by the release of hydrogen bromide. In turn, the photogenerated acid encourages the opening of an oxazine ring embedded within a halochromic compound. This structural transformation extends the conjugation of an adjacent coumarin fluorophore and enables its absorption at an appropriate excitation wavelength. Indeed, this bimolecular system offers the opportunity to activate fluorescence in liquid solutions, within rigid matrixes and inside micellar assemblies, relying on the interplay of activating and exciting beams. Furthermore, this strategy permits the permanent imprinting of fluorescent patterns on polymer films, the monitoring of proton diffusion within such materials in real time on a millisecond time scale, and the acquisition of images with spatial resolution at the nanometer level. Thus, our operating principles for fluorescence activation can eventually lead to the development of valuable photoswitchable probes for imaging applications and versatile mechanisms for the investigation of proton transport.

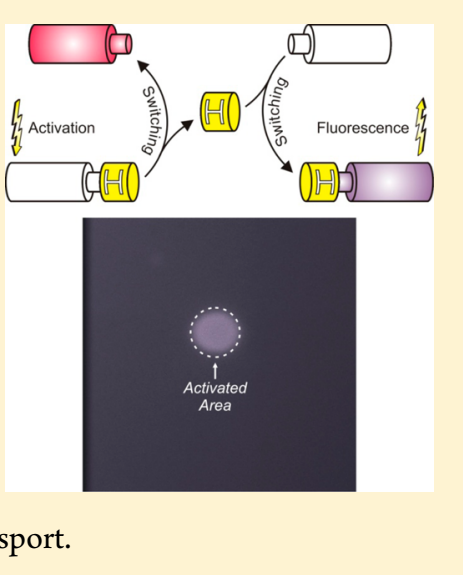

\section{INTRODUCTION}

Fluorescence microscopy ${ }^{1}$ is an invaluable analytical tool for the structural investigation of materials at the micrometer level. It is based on the introduction of appropriate fluorescent labels ${ }^{2}$ within a sample of interest and the subsequent acquisition of images, after the excitation of the probes and the collection of their emission. The development of fluorophores with optimal photochemical and photophysical properties, as well as of efficient and versatile labeling protocols, is therefore of central importance for the further advancement of this convenient imaging technique. In particular, the identification of mechanisms to photoactivate fluorescence ${ }^{3-8}$ can facilitate the elucidation of dynamic processes in real time $e^{9-14}$ and the visualization of structural features with subdiffraction resolution. ${ }^{15-22}$ Indeed, probes able to switch from a nonemissive state to a fluorescent one under optical control offer the opportunity to monitor the translocation of labeled species within a material. Similarly, these switching events permit the separation of spatially indistinguishable labels in time and the sequential reconstruction of images with resolution at the nanometer level.

Most photoactivatable fluorophores are designed around the ability of one or more photocleavable groups to dissociate from an emissive chromophore, upon illumination at an appropriate wavelength. ${ }^{3-8}$ This photochemical transformation alters the electronic structure of the chromophore, and either enables its absorption of an exciting radiation or discourages the nonradiative decay of its excited state. Both mechanisms translate into fluorescence activation. Inspired by our earlier work on photoinduced proton transfer, ${ }^{23}$ we designed an alternative strategy to photoinduce the activation of fluorescence. Specifically, we envisaged the possibility of combining a molecule capable of releasing acid upon illumination with an emissive halochromic compound. In the resulting bimolecular system, the photoinduced transfer of a proton from the former to the latter can be exploited to control the electronic structure of the emissive species and activate its fluorescence. Indeed, such a mechanism to activate fluorescence demands the intermolecular communication of two independent components, rather than the dissociation of a single molecular species. Therefore, it offers the unique opportunity to probe the signal (i.e., a proton) propagating from one component to the other with fluorescence measurements. In this article, we report the implementation of these operating principles for fluorescence photoactivation in liquid solutions, within rigid matrixes and inside micellar assemblies, as well as the application of this strategy to monitor the diffusion of protons within polymer films in real time and to reconstruct fluorescence images with subdiffraction resolution.

Received: August 6, 2012

Revised: September 18, 2012

Published: September 20, 2012 


\section{RESULTS AND DISCUSSION}

Spectroscopy. The covalent backbone of 1 (Figure 1) incorporates a coumarin fluorophore and an oxazine switch and

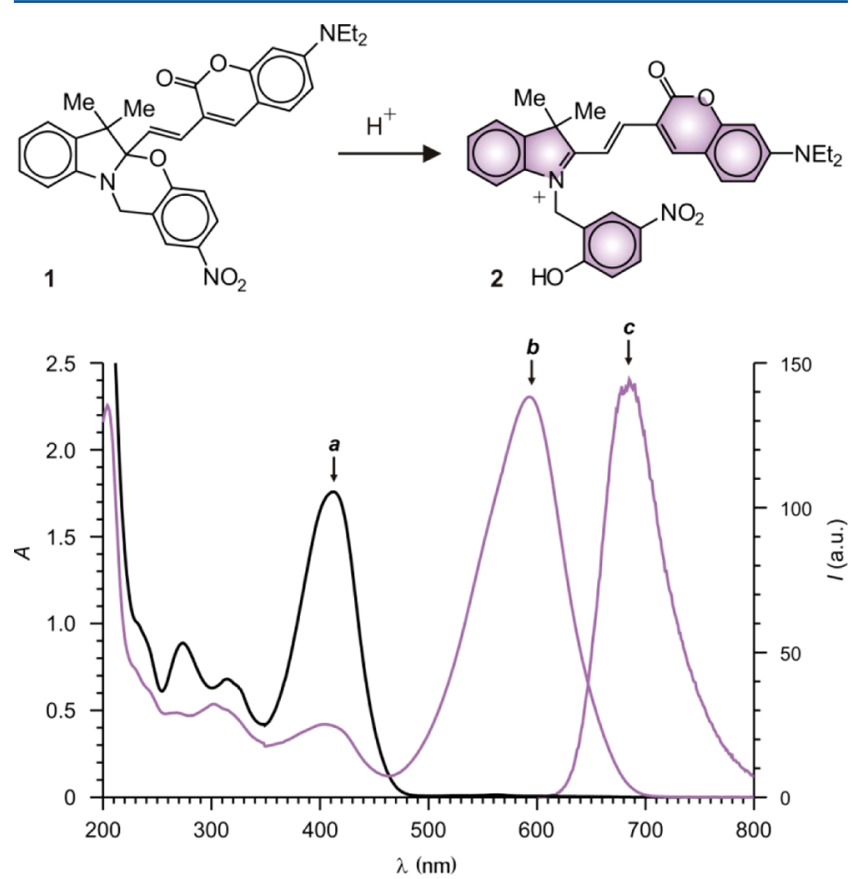

Figure 1. Absorption spectra of a solution $\left(0.1 \mathrm{mM}, \mathrm{MeCN}, 25^{\circ} \mathrm{C}\right)$ of 1 recorded before (a) and after (b) the addition of TFA (1 equiv). Emission spectrum $\left(\lambda_{\mathrm{Ex}}=590 \mathrm{~nm}\right)$ of the acidified solution $(\mathrm{c})$.

can be assembled in a single synthetic step from known precursors. $^{24}$ The absorption spectrum (Figure 1a) of an acetonitrile solution of this compound shows a band centered at $412 \mathrm{~nm}$ for the coumarin appendage. Upon the addition of a single equivalent of trifluoroacetic acid (TFA), this band decreases in intensity, and a new one appears at $593 \mathrm{~nm}$ in the corresponding spectrum (Figure $1 \mathrm{~b}$ ). This pronounced spectral change is a result of the opening of the oxazine ring with the formation of $\mathbf{2}$. Indeed, such structural transformation brings the coumarin fluorophore in conjugation with the adjacent $3 \mathrm{H}$ indolium cation and shifts its main absorption bathochromically. In turn, the illumination of the resulting solution at an excitation wavelength $\left(\lambda_{\mathrm{Ex}}\right)$ comprised within this band excites selectively the coumarin fragment of $\mathbf{2}$ with concomitant fluorescence. In fact, the corresponding emission band (Figure 1c) can be observed at $685 \mathrm{~nm}$ only after the addition of acid, demonstrating that the halochromic transformation of $\mathbf{1}$ into 2 can be exploited to activate fluorescence.

The halochromic conversion of $\mathbf{1}$ into $\mathbf{2}$ can be encouraged with the assistance of a compound able to release acid under illumination at an appropriate activation wavelength $\left(\lambda_{\mathrm{Ac}}\right)$. Indeed, a molecule capable of transferring a proton to $\mathbf{1}$ upon irradiation can mediate the photochemical formation of $\mathbf{2}$ and activate fluorescence. For example, the established photochemistry of the 2-nitrobenzyl group ${ }^{4,5}$ can be adapted to photogenerate acid. ${ }^{25}$ Specifically, the photolysis of 3 (Figure 2) results in the formation of $\mathbf{4}$ and hydrogen bromide. Consistently, the absorption spectra, recorded before (Figure $2 \mathrm{a}$ ) and during (Figure $2 \mathrm{~b}-\mathrm{f}$ ) the course of irradiation at $\lambda_{\mathrm{Ac}}$ in acetonitrile, reveal a decrease in the absorbance associated with 3 at $249 \mathrm{~nm}$ and the concomitant appearance of a new band for 4 at ca. $400 \mathrm{~nm}$. In the presence of equimolar amounts of 1 and
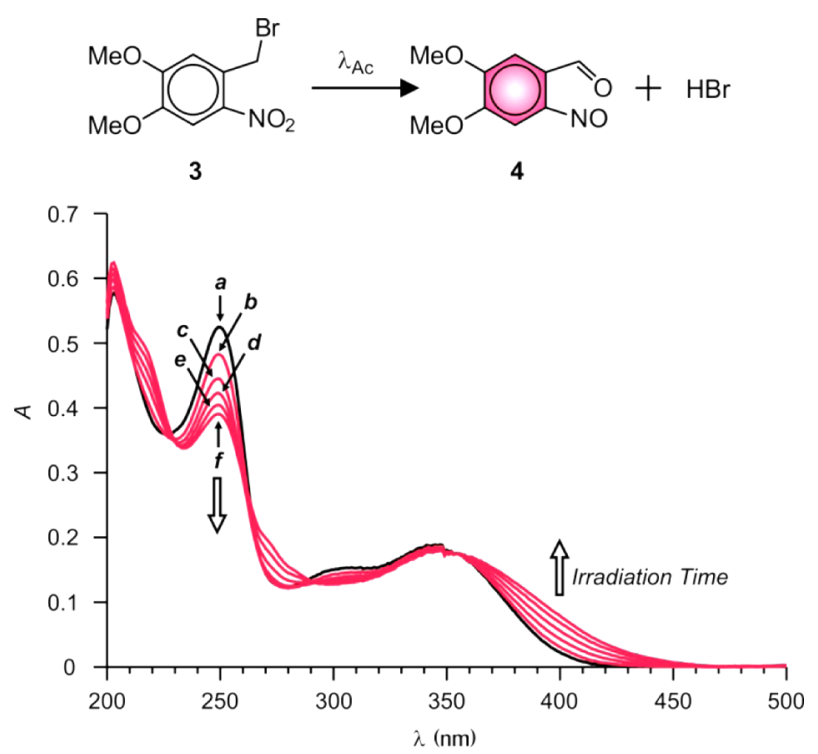

Figure 2. Absorption spectra of a solution $\left(0.1 \mathrm{mM}, \mathrm{MeCN}, 25^{\circ} \mathrm{C}\right)$ of 3 recorded before (a) and after irradiation $\left(\lambda_{\mathrm{Ac}}=365 \mathrm{~nm}, 0.4 \mathrm{~mW}\right.$ $\mathrm{cm}^{-2}$ ) for 1 (b), 2 (c), 3 (d), 4 (e), and $5 \mathrm{~min}(\mathrm{f})$.

under otherwise identical conditions, the photolysis of 3 causes essentially the same bathochromic shift observed for $\mathbf{1}$ after the addition of TFA. ${ }^{26}$ Once again, the initial absorption spectrum (Figure 3a) shows a band at $412 \mathrm{~nm}$ for the coumarin

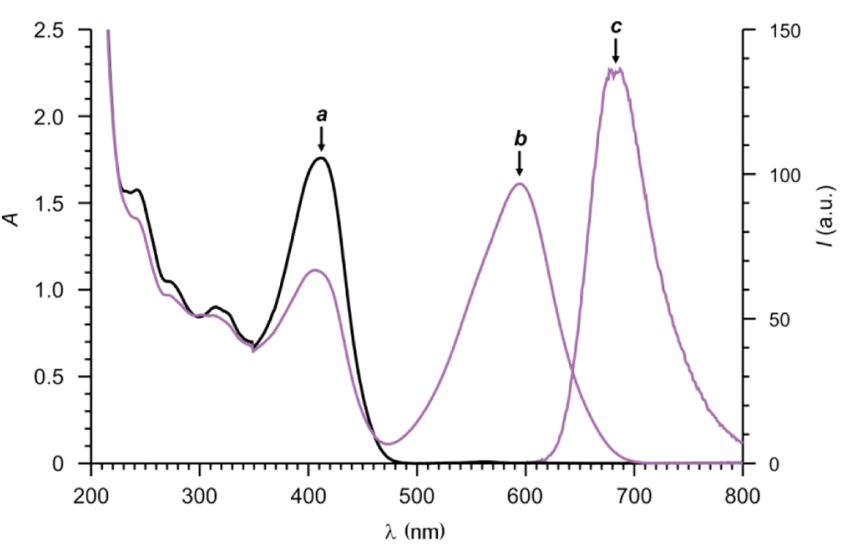

Figure 3. Absorption spectra of an equimolar solution $(0.1 \mathrm{mM}$, $\mathrm{MeCN}, 25^{\circ} \mathrm{C}$ ) of 1 and 3 recorded before (a) and after (b) irradiation $\left(\lambda_{\mathrm{Ac}}=365 \mathrm{~nm}, 0.4 \mathrm{~mW} \mathrm{~cm}^{-2}, 5 \mathrm{~min}\right)$. Emission spectrum $\left(\lambda_{\mathrm{Ex}}=590\right.$ $\mathrm{nm})$ of the irradiated solution (c).

appendage of 1 . After illumination at $\lambda_{\mathrm{Ac}}$ (Figure $3 \mathrm{~b}$ ), the absorbance of this band decreases with the concomitant appearance of a new band at $595 \mathrm{~nm}$ for the extended cationic chromophore of $\mathbf{2}$. Irradiation of the resulting solution at $\lambda_{\mathrm{Ex}}$ excites selectively the coumarin fragment of the protonated species and is accompanied by the appearance of a characteristic emission band (Figure 3c) of 2 at $687 \mathrm{~nm}$. Thus, the acid released during the course of the photochemical conversion of 3 into 4 encourages the protonation of $\mathbf{1}$ with the formation of 2 and activates fluorescence.

The photoinduced transformation of $\mathbf{1}$ into $\mathbf{2}$ can be reproduced within a rigid polymer matrix, once again, under the assistance of 3. As observed in acetonitrile, the absorption spectrum (Supplementary Figure S1a) of a poly(n-butyl methacrylate) (PBMA) film, doped with equimolar amounts 

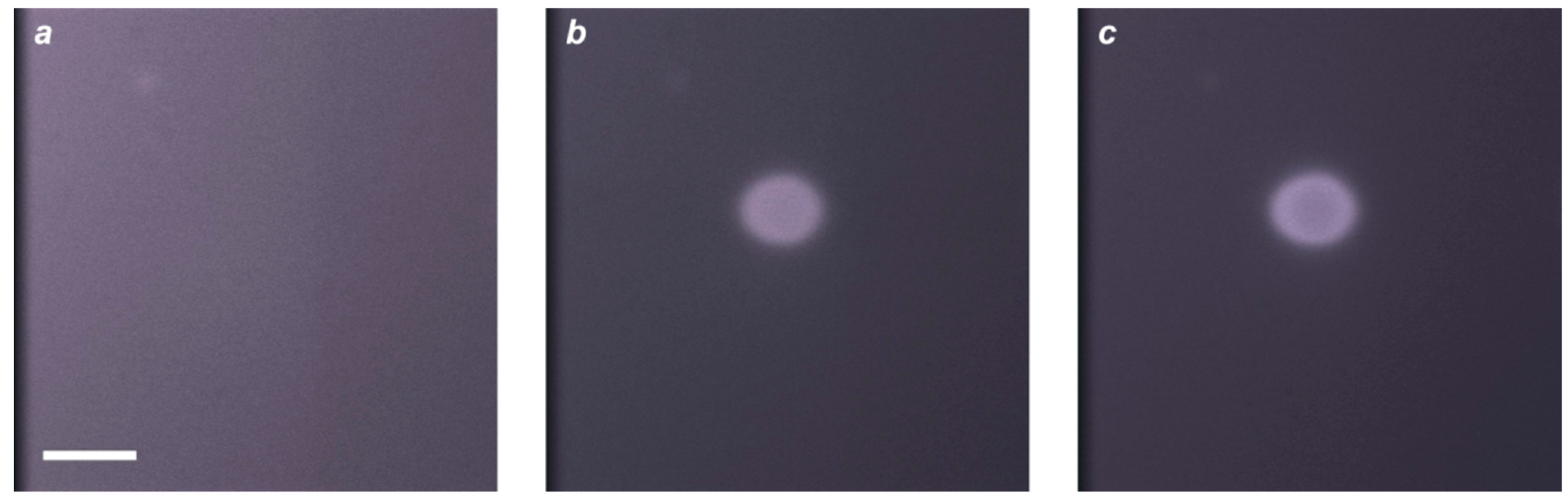

Figure 4. Confocal laser-scanning fluorescence images $\left(\lambda_{\mathrm{Ex}}=514 \mathrm{~nm}, 40 \mu \mathrm{W}, \lambda_{\mathrm{Em}}=600-800 \mathrm{~nm}\right.$, scale bar $\left.=5 \mu \mathrm{m}\right)$ of a PBMA film, doped with 1 $(2 \% \mathrm{w} / \mathrm{w})$ and $3(1 \% \mathrm{w} / \mathrm{w})$ and spin-coated on a glass slide, recorded before $(\mathrm{a})$, immediately after $(\mathrm{b})$, and 5 min after $(\mathrm{c})$ laser illumination $\left(\lambda_{\mathrm{Ac}}=\right.$ $405 \mathrm{~nm}, 1 \mathrm{~mW}, 1 \mathrm{~s})$ of a circular spot within the imaging field.

of 1 and 3 and spin-coated on quartz, shows a band at $399 \mathrm{~nm}$ for the coumarin chromophore of $\mathbf{1}$. After irradiation at $\lambda_{\mathrm{Ac}}$ (Supplementary Figure S1b), the absorbance of this band decreases, and a new one develops at $606 \mathrm{~nm}$ in agreement with the formation of $2 .{ }^{26}$ Irradiation at $\lambda_{\mathrm{Ex}}$ excites the coumarin appendage of the protonated species and results in the appearance of the characteristic emission band (Supplementary Figure S1c) of 2 at $685 \mathrm{~nm}$. Thus, the acid generated during the photochemical conversion of 3 into 4 can diffuse within the relatively rigid and hydrophobic polymer matrix to encourage the halochromic transformation of $\mathbf{1}$ into $\mathbf{2}$ with concomitant fluorescence activation.

Ensemble Imaging. Confocal laser-scanning fluorescence images of PBMA films doped with $\mathbf{1}$ and $\mathbf{3}$ reveal the appearance of fluorescent patterns only after photoinduced activation. In particular, the image (Figure 4a) recorded with a $\lambda_{\text {Ex }}$ of $514 \mathrm{~nm}$, where neither 1 nor 3 absorb, does not show any significant fluorescence. After illumination at a $\lambda_{\mathrm{Ac}}$ of $405 \mathrm{~nm}$ exclusively within a circular spot at the center of the imaging field, however, the image (Figure $4 \mathrm{~b}$ ) recorded with the same $\lambda_{\text {Ex }}$ clearly reveals fluorescence activation. ${ }^{27}$ Indeed, the beam at $\lambda_{\mathrm{Ac}}$ induces first the transformation of $\mathbf{3}$ into $\mathbf{4}$ and then that of 1 into 2 within the illuminated spot, while that at $\lambda_{\mathrm{Ex}}$ excites selectively the photogenerated species $\mathbf{2}$ and produces fluorescence in the activated area. Furthermore, the very same fluorescent pattern can be observed again in the image (Figure 4c) recorded after $5 \mathrm{~min}$ from activation, demonstrating that $\mathbf{2}$ cannot diffuse within the polymer film.

The observed activation of fluorescence is indicative of proton diffusion within the polymer matrix. Indeed, the hydrogen bromide released from 3 upon irradiation must be able to travel within the film and reach 1 in order to encourage the formation of the fluorescent species 2 . In fact, proton diffusion can be monitored in real time with the sequential acquisition of frames under simultaneous illumination at $\lambda_{\mathrm{Ac}}$ and $\lambda_{\mathrm{Ex}}$ to activate 3 and excite 2 , respectively. Specifically, the irradiation at $\lambda_{\mathrm{Ac}}$ of a rectangular area at the top edge of the imaging field generates acid only within the illuminated region. As a result, the simultaneous irradiation of the entire imaging field at $\lambda_{\mathrm{Ex}}$ reveals fluorescence only within the activated area in the initial frame (Figure 5a). The subsequent acquisition of frames (Figure 5b,c) at intervals of $50 \mathrm{~ms}$ under these illumination conditions, however, show a gradual increase in fluorescence outside the activated area. ${ }^{28}$ This behavior suggests that a fraction of the photogenerated hydrogen
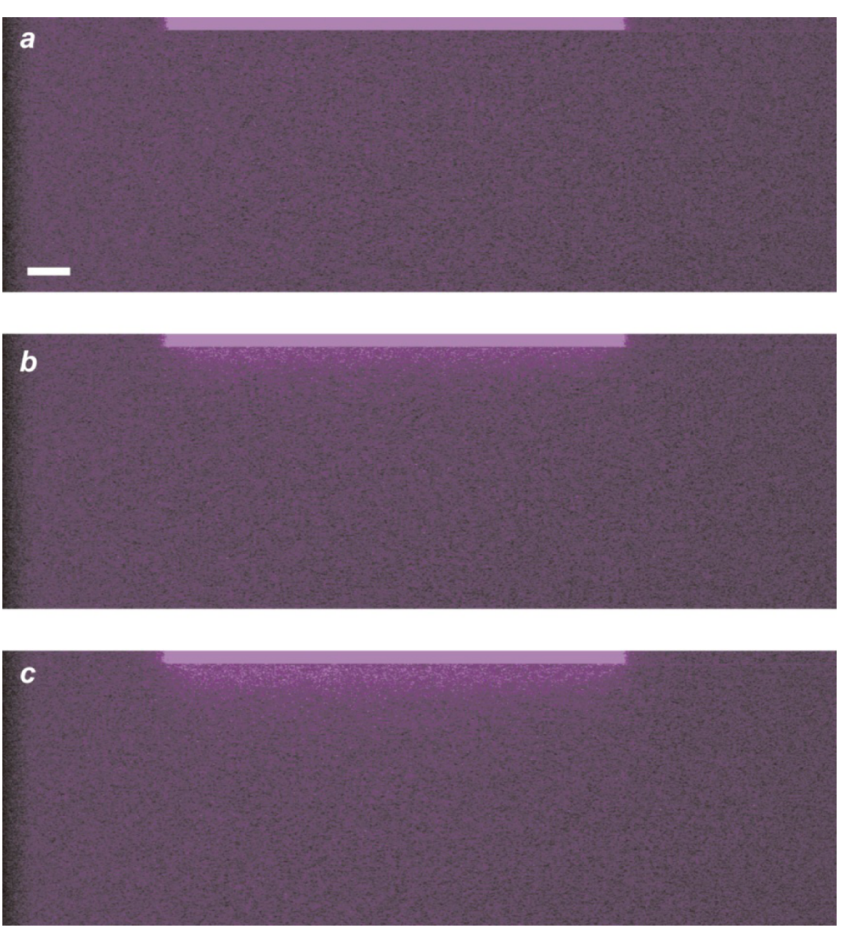

Figure 5. Confocal laser-scanning fluorescence images $\left(\lambda_{\mathrm{Ex}}=514 \mathrm{~nm}\right.$, $7 \mu \mathrm{W}, \lambda_{\mathrm{Em}}=600-800 \mathrm{~nm}$, scale bar $\left.=5 \mu \mathrm{m}\right)$ of a PBMA film, doped with $1(2 \% \mathrm{w} / \mathrm{w})$ and $3(1 \% \mathrm{w} / \mathrm{w})$ and spin-coated on a glass slide, recorded during laser illumination $\left(\lambda_{\mathrm{Ac}}=405 \mathrm{~nm}, 1 \mathrm{~mW}\right)$ of a rectangular area at the top edge of the imaging field with a frame interval of $50 \mathrm{~ms}(\mathrm{a}=$ frame $1, \mathrm{~b}=$ frame 250 , and $\mathrm{c}=$ frame 500$){ }^{28}$

bromide eventually diffuses out of the activated area and encourages the formation of the fluorescent species $\mathbf{2}$ along its path, until it is completely consumed over the course of a few seconds.

Single-Molecule Imaging. The photoinduced proton transfer from 3 to $\mathbf{1}$ can be a valuable alternative to the mechanisms for fluorescence switching currently employed to acquire subdiffraction images with far-field optics. ${ }^{15-22}$ In particular, the emission properties of the coumarin fluorophore incorporated within the resulting protonated form 2 , which allow its detection at the single-molecule level, ${ }^{24 \mathrm{~b}}$ and the thermal stability of this species (i.e., the irreversibility of the switching-on process), suggest the application of this bimolecular system in stochastic single-molecule localization 
superresolution schemes. In order to test this possibility, $\mathbf{1}$ and 3 were incorporated within the hydrophobic core of micellar assemblies of an amphiphilic copolymer ( 5 in Supplementary Figure S2). This particular macromolecular construct incorporates multiple hydrophilic poly(ethylene glycol) and hydrophobic decyl chains along a common poly(acrylate) backbone and forms micelles with a diameter of ca. $14 \mathrm{~nm}$ that are able to encapsulate hydrophobic dyes in their interior. ${ }^{29}$ Furthermore, the polymeric envelope provides an environment to its guests similar to that experienced by $\mathbf{1}$ and $\mathbf{3}$ within the PBMA films employed for the ensemble activation experiments (Figures 4, 5 , and S1). These micelles were spin coated onto a glass slide and imaged in a home-built wide-field epi-fluorescence microscope, equipped with two illumination sources and a fast and sensitive electron multiplying charge couple device (EMCCD) camera. One of the light sources was operated at $405 \mathrm{~nm}$ to activate the photoacid 3 and the other at $532 \mathrm{~nm}$ to excite the protonated species 2 . Typical measurements consisted in an independent running acquisition scheme $\mathrm{s}^{30}$ with a frame time of $20 \mathrm{~ms}$. The samples were continuously excited in wide-field mode with the $532 \mathrm{~nm}$ beam, and an activation pulse of $405 \mathrm{~nm}$ was used, during the camera readout time, to keep a sparse distribution of bright molecules in the observation area. High excitation intensity was applied in order to bleach the observed fluorophores with an average characteristic time of the order of the frame time. In a representative image (Figure $6 \mathrm{~b}$ ) reconstructed with this approach, fluorescent objects can clearly be observed with a significant improvement in resolution relative to the diffraction-limited counterpart (Figure 6a). The profiles (Figure 6c) of the emission intensity measured along one of the objects in the two images reveal an improvement in spatial resolution from ca. $270 \mathrm{~nm}$ to ca. 40 $\mathrm{nm}$. These physical dimensions are in accordance with the values expected on the basis of the detection wavelengths (centered at $640 \mathrm{~nm}$ ), numerical aperture (1.25) of the objective lens, and the average number (76) of detected photons per event. The time evolution (Figure $6 \mathrm{~d}$ ) of the single-molecule events detected per frame shows a clear decrease over the course of the experiment. The activation dose was increased sequentially (indicated with black arrows) to speed the measurements by sustaining a reasonable amount of events, while keeping the emissive species at an average distance considerably larger than the resolution of the microscope. Normally, a measurement was terminated when the amount of events reached a very low value and could not be enhanced by increasing the activation dose. Further representative images (Figure 7) show that the increase in resolution translates into the opportunity to distinguish pairs of fluorescent objects that are otherwise blurred in their conventional diffraction-limited counterparts. Thus, this mechanism for fluorescence activation can, indeed, overcome diffraction and permit the imaging of objects with spatial resolution in the nanoscale. Furthermore, the absorption properties of the photoacid 3 allow fluorescence activation with visible light and therefore offer the opportunity to avoid altogether ultraviolet radiations and their harmful consequences on biological specimens.

\section{CONCLUSIONS}

Our results demonstrate that the release of acid from a 2nitrobenzyl derivative, upon irradiation at an activating wavelength, can be exploited to induce a halochromic transformation within a coumarin-oxazine dyad. The coumarin
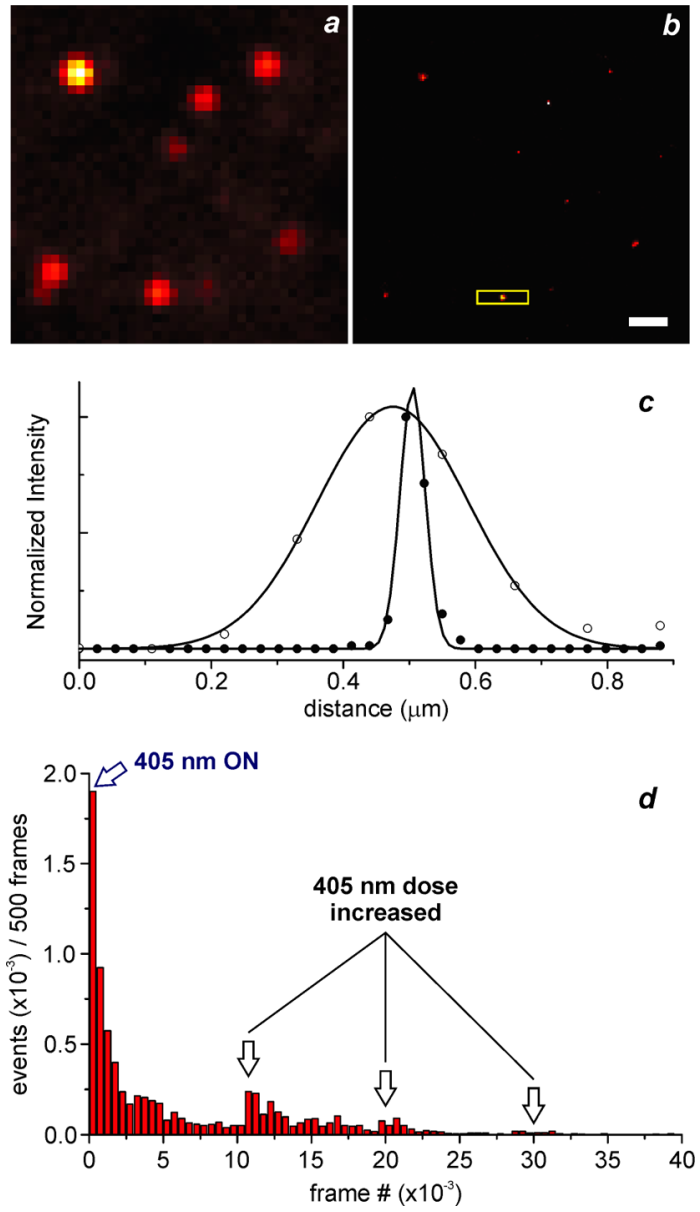

Figure 6. Conventional (a) and superresolution (b) images (scale bar $=500 \mathrm{~nm}$ ) of micellar assemblies (diameter $=14 \mathrm{~nm}$ ) of $\mathbf{5}$, doped with 1 and 3 and spin coated on a glass slide. Emission intensity profiles (c) measured along the bright object shown in the yellow inset (average of 3 lines); Gaussian fits indicate full-widths at half-maximum of 270 and $42 \mathrm{~nm}$, respectively, in agreement with the expected values. Frequency count (d) of the events localized during a frame-series recording; the activating laser $(405 \mathrm{~nm})$ was switched on with an initial low dose and a pulse width of $20 \mu \mathrm{s}$, which was then increased to $200 \mu \mathrm{s}, 400 \mu \mathrm{s}$, and $2.5 \mathrm{~ms}$, respectively, at the frames indicated by the black arrows.

appendage within the halochromic product can then be excited selectively with concomitant fluorescence, under illumination at an appropriate excitation wavelength. In fact, this bimolecular system offers the opportunity to photoactivate fluorescence in liquid solution, within rigid matrixes and inside micellar assemblies, relying on the interplay of activating and exciting beams. Furthermore, fluorescent patterns can be imprinted permanently in PBMA films doped with both the photoacid generator and the emissive halochromic compound. This choice of functional components permits also the monitoring of proton diffusion from one component to the other within the relatively rigid and hydrophobic polymer matrix in real time. In addition, this bimolecular system can be exploited to overcome diffraction and reconstruct images with resolution at the nanometer level, relying exclusively on far-field optics and visible wavelengths. Thus, our operating principles for fluorescence activation can ultimately lead to the development of valuable probes for imaging applications and the investigation of proton transport in a diversity of materials. 

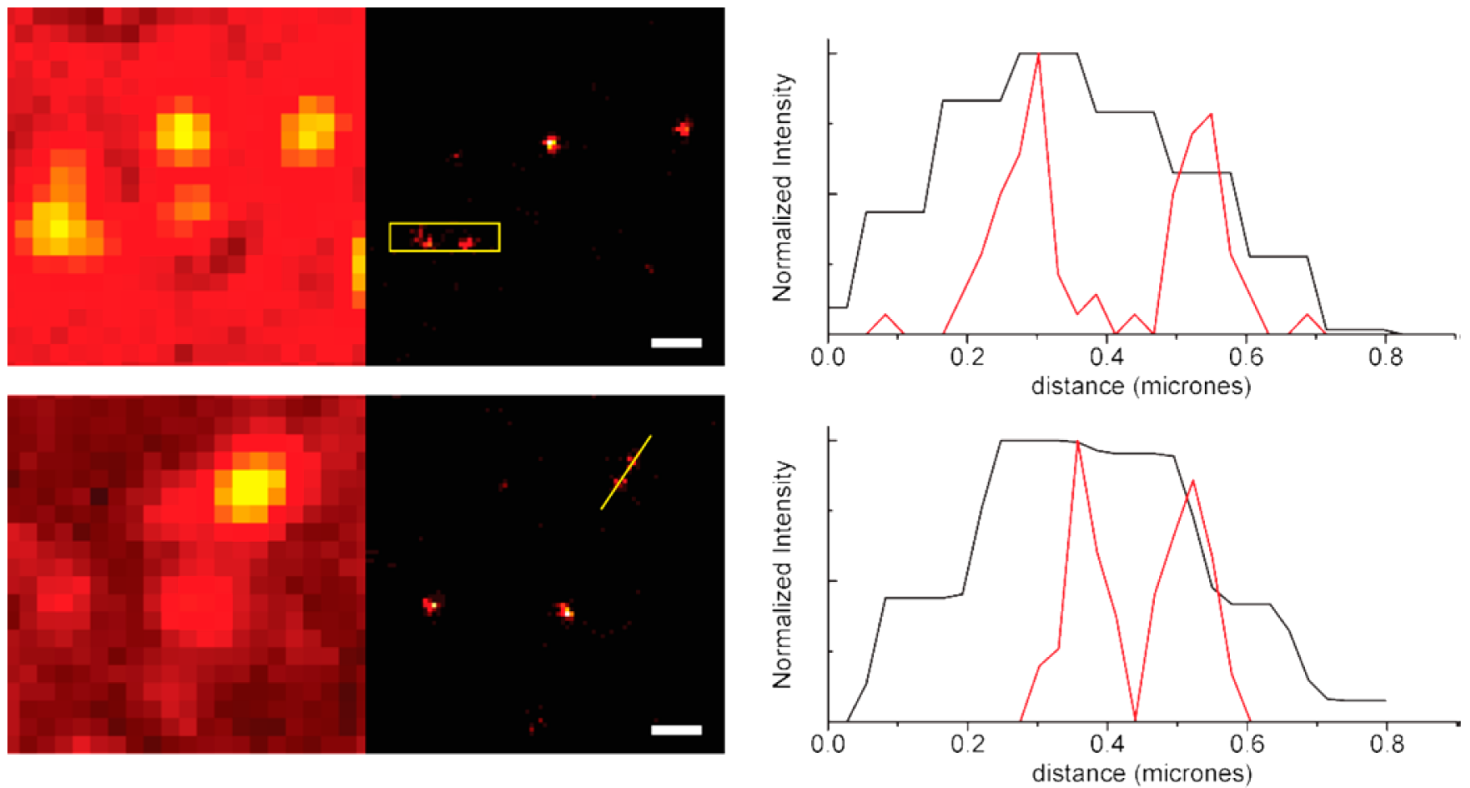

Figure 7. Conventional and super-resolution images (scale bar $=300 \mathrm{~nm}$ ) of micellar assemblies (diameter $=14 \mathrm{~nm}$ ) of $\mathbf{5}$, doped with $\mathbf{1}$ and 3 and spin coated on a glass slide, together with profiles of the emission intensity measured along the indicated lines. The brightest objects may be agglomerates of a few micelles, unresolved in both images, while the dimer ones are presumably single micelles.

\section{EXPERIMENTAL PROCEDURES}

Materials. Chemicals were purchased from commercial sources and used as received with the exception of $\mathrm{MeCN}$, which was distilled over $\mathrm{CaH}_{2}$. Compounds 1 and 5 were prepared according to literature procedures. ${ }^{24 a, 29 a}$ Doped polymer films were prepared by spin coating $\mathrm{CH}_{2} \mathrm{Cl}_{2}$ solutions of PBMA $\left(M_{\mathrm{w}}=337 \times 10^{3}, 156 \mathrm{mg} \mathrm{mL}^{-1}\right)$ and $1(3.0 \mathrm{mg}$ $\left.\mathrm{mL}^{-1}\right)$ with and without $3\left(1.5 \mathrm{mg} \mathrm{mL}^{-1}\right)$ with a Chemat Technologies KW-4A spin coater at $390 \mathrm{rpm}$ for $18 \mathrm{~s}$ and then at $790 \mathrm{rpm}$ for $60 \mathrm{~s}$ on quartz disks for the spectroscopic measurements and on glass coverslips for the imaging experiments. The thickness of the polymer films $(<10 \mu \mathrm{m})$ was measured with a Mitutoyo digital micrometer. Doped polymer micelles were prepared by combining $\mathrm{CHCl}_{3}$ solutions of $1\left(0.1 \mathrm{mg} \mathrm{mL}^{-1}, 50 \mu \mathrm{L}\right), 3\left(0.1 \mathrm{mg} \mathrm{mL}^{-1}, 50 \mu \mathrm{L}\right)$, and $5(2.5$ $\left.\mathrm{mg} \mathrm{mL} \mathrm{mL}^{-1}, 200 \mu \mathrm{L}\right)$ and heating the resulting mixture at $40{ }^{\circ} \mathrm{C}$ in an open vial. After the evaporation of the solvent, the residue was purged with air and dispersed in phosphate buffer saline (PBS, $1 \mathrm{~mL}, \mathrm{pH}=7.0$ ). After vigorous shaking, the dispersion was filtered, and the filtrate was spin coated at $1000 \mathrm{rpm}$ for 20 s with a Laurell Tech. Corp. WS-400B-6NPP/lite spin coater on glass coverslips that were previously cleaned with $\mathrm{O}_{3}$ for 20 min using a Jelight Company Inc. UVO Cleaner 42.

Methods. Absorption spectra were recorded with a Varian Cary 100 Bio spectrometer, using quartz cells with a path length of $0.5 \mathrm{~cm}$. Emission spectra were recorded with a Varian Cary Eclipse spectrometer in aerated solutions. Custom-built sample holders were used to record the absorption and emissions spectra of the polymer films. Samples were irradiated at $365 \mathrm{~nm}\left(0.4 \mathrm{~mW} \mathrm{~cm}^{-2}\right)$ with a Mineralight UVGL-25 lamp. Ensemble fluorescence images were recorded with a Leica SP5 confocal laser-scanning microscope. Single-molecule fluorescence images were recorded with a custom-built wide-field epifluorescence microscope. Excitation was performed with a continuous-wave (CW) diode-pumped solid-state Shanghai Dream Lasers Technology Co. SDL-532-LM-200-T laser operating at a $532 \mathrm{~nm}$ with an intensity of $7 \mathrm{~kW} \mathrm{~cm} \mathrm{~cm}^{-2}$ calculated at the focal plane. Activation was performed with a CW diode Shanghai Dream Lasers Technology Co. SDL-405LM-20-T laser operating at $405 \mathrm{~nm}$ with an intensity lower than $100 \mathrm{~W} \mathrm{~cm}^{-2}$. While the excitation laser was continuously running, the activation laser was switched on for short periods during camera read-out. The duration of the activation pulse was changed from 50 to $500 \mu \mathrm{s}$ and, therefore, the longest pulses had some overlap with the frame recording. Nevertheless, no increase in background signal was observed because of the low activation intensity. The lasers were combined in one beam with a Chroma Technology Corp. ZT405rdc dichroic mirror, and illumination was performed in wide-field mode by focusing both lasers in the back focal plane of a $63 \times$ oilimmersion Olympus objective lens with a numerical aperture of 1.25. The fluorescence signal was collected by the same objective, separated from activation and excitation light by a Chroma Technology Corp. ZT532rdc dichroic mirror, further cleaned with a Semrock Inc. NF01-532U-25 notch filter and a Semrock Inc. FF01-640/40 bandpass filter and then detected by an Andor Technology IXON-DU-897 EMCCD camera. Typically, sets of 20000-50000 frames were collected, and localization of single-molecule events and image reconstruction were performed as previously described. ${ }^{30}$

\section{ASSOCIATED CONTENT}

\section{S Supporting Information}

Absorption and emission spectra of a PBMA film doped with 1 and 3; movie of a PBMA film doped with 1 and 3; structure of the amphiphilic copolymer 5; ref 30 . This material is available free of charge via the Internet at http://pubs.acs.org.

\section{AUTHOR INFORMATION}

\section{Corresponding Author}

*E-Mail: mariano@qi.fcen.uba.ar (M.L.B.); fraymo@miami.edu (F.M.R.).

Notes

The authors declare no competing financial interest. 


\section{ACKNOWLEDGMENTS}

M.L.B. is a member of "Carrera del Investigador Cientifico" from CONICET (National Research Council of Argentina), and part of this work was performed under financial support from the Max Planck Society (Partner Group Grant), ANPCyT, and UBACyT. He is also grateful to Professor Stefan W. Hell for constant support. F.M.R. thanks the National Science Foundation (CAREER Award CHE0237578, CHE-0749840, and CHE-1049860) for supporting his research program and for providing funds to purchase a mass spectrometer (CHE-0946858).

\section{REFERENCES}

(1) Murphy, D. B. Fundamentals of Light Microscopy and Electronic Imaging; Wiley-Liss: New York, 2001.

(2) Lakowicz, J. R. Principles of Fluorescence Spectroscopy; Springer: New York, 2006.

(3) Mitchison, T. J.; Sawin, K. E.; Theriot, J. A.; Gee, K.; Mallavarapu, A. Methods Enzymol. 1998, 291, 63-78.

(4) Pelliccioli, A. P.; Wirz, J. Photochem. Photobiol. Sci. 2002, 1, 441458.

(5) Goeldner, M., Givens, R., Eds. Dynamic Studies in Biology: Phototriggers, Photoswitches and Caged Biomolecules; Wiley-VCH: Weinheim, Germany, 2005.

(6) Puliti, D.; Warther, D.; Orange, C.; Specht, A.; Goeldner, M. Bioorg. Med. Chem. 2011, 19, 1023-1029.

(7) Wysocki, L. M.; Davis, L. D. Curr. Opin. Chem. Biol. 2011, 15, $752-759$.

(8) Li, W.-H.; Zhneg, G. Photochem. Photobiol. Sci. 2012, 11, 460471.

(9) Krafft, G. A.; Cummings, R. T.; Dizio, J. P.; Furukawa, R. H.; Brvenik, L. J.; Sutton, W. R.; War, B. R. In Nucleocytoplasmic Transport; Peters, R., Trendelenburg, M., Eds.; Springer-Verlag: Berlin, Germany, 1986; pp 35-52.

(10) Adams, S. R.; Tsien, R. Y. Annu. Rev. Physiol. 1993, 55, 755784.

(11) Politz, J. C. Trends Cell Biol. 1999, 9, 284-287.

(12) (a) Lippincott-Schwartz, J.; Altan-Bonnet, N.; Patterson, G. H. Nat. Cell Biol. 2003, 5, S7-S14. (b) Lippincott-Schwartz, J.; Patterson, G. H. Science 2003, 300, 87-91. (c) Manley, S.; Gillette, J. M.; Lippincott-Schwartz, J. Methods Enzymol. 2010, 475, 109-120.

(13) Ellis-Davies, G. C. Nat. Methods 2007, 4, 619-628.

(14) Johnson, I.; Spence, M. T. Z. The Molecular Probes Handbook: A Guide to Fluorescent Probes and Labeling Technologies: 11th ed.; Life Technologies: Carlsbad, CA, 2010.

(15) (a) Hell, S. W. Nat. Biotechnol. 2003, 21, 1347-1355. (b) Hell, S. W. Science 2007, 316, 1153-1158. (c) Hell, S. W. Nat. Methods 2009, 6, 24-32.

(16) (a) Sauer, M. Proc. Natl. Acad. Sci. U.S.A. 2005, 105, 94339434. (b) van de Linde, S.; Wolter, S.; Sauer, M. Aust. J. Chem. 2011, 64, 503-511. (c) van de Linde, S.; Heilemann, M.; Sauer, M. Annu. Rev. Phys. Chem. 2012, 63, 519-540.

(17) Fernández-Suárez, M.; Ting, A. Y. Nat. Rev. Mol. Cell. Biol. 2008, 9, 929-943.

(18) (a) Bates, M.; Huang, B.; Zhuang, X. Curr. Opin. Chem. Biol. 2008, 12, 505-514. (b) Huang, B.; Bates, M.; Zhuang, X. Annu. Rev. Biochem. 2009, 78, 993-1016. (c) Vaughan, J. C.; Zhuang, X. Nat. Biotechnol. 2011, 29, 880-881.

(19) (a) Hess, S. T.; Gould, T. J.; Gunewardene, M.; Bewersdorf, J.; Mason, M. D. Methods Mol. Biol. 2009, 2009, 483-522. (b) Toomre, D.; Bewersdorf, J. Annu. Rev. Cell Dev. Biol. 2010, 26, 285-314.

(20) (a) Vogelsang, J.; Steinhauer, C.; Forthmann, C.; Stein, I. H.; Person-Skergo, B.; Cordes, T.; Tinnefeld, P. ChemPhysChem 2010, 11, 2475-2490. (b) Ha, T.; Tinnefeld, P. Annu. Rev. Phys. Chem. 2012, 63, $595-617$.
(21) (a) Thompson, M. A.; Biteen, J. S.; Lord, S. J.; Conley, N.; Moerner, W. E. Methods Enzymol. 2010, 475, 27-59. (b) Moerner, W. E. J. Microsc. 2012, 246, 213-220.

(22) Cusido, J.; Impellizzeri, S.; Raymo, F. M. Nanoscale 2011, 3, $59-70$.

(23) (a) Raymo, F. M.; Giordani, S. Org. Lett. 2001, 3, 3475-3478. (b) Raymo, F. M.; Alvarado, R. J.; Giordani, S.; Cejas, M. A. J. Am. Chem. Soc. 2003, 125, 2361-2364. (c) Giordani, S.; Cejas, M. A.; Raymo, F. M. Tetrahedron 2004, 60, 10973-10981. (d) Silvi, S.; Arduini, A.; Pochini, A.; Secchi, A.; Tomasulo, M.; Raymo, F. M.; Baroncini, M.; Credi, A. J. Am. Chem. Soc. 2007, 129, 13378-13379. (e) Silvi, S.; Constable, E. C.; Housecroft, C. E.; Beves, J. E.; Dunphy, E. L.; Tomasulo, M.; Raymo, F. M.; Credi, A. Chem.-Eur. J. 2009, 15, 178-185. (f) Silvi, S.; Constable, E. C.; Housecroft, C. E.; Beves, J. E.; Dunphy, E. L.; Tomasulo, M.; Raymo, F. M.; Credi, A. Chem. Commun. 2009, 1484-1486.

(24) (a) Deniz, E.; Sortino, S.; Raymo, F. M. J. Phys. Chem. Lett. 2010, 1, 3506-3509. (b) Deniz, E.; Tomasulo, M.; Cusido, J.; Yildiz, I.; Petriella, M.; Bossi, M. L.; Sortino, S.; Raymo, F. M. J. Phys. Chem. C 2012, 116, 6058-6068.

(25) Houlihan, M.; Shugard, A.; Gooden, R.; Reichmanis, E. Macromolecules 1988, 21, 2001-2006.

(26) The absorption spectra of $\mathbf{1}$ in acetonitrile and PBMA do not change upon irradiation at $\lambda_{\mathrm{Ac}}$ in the absence of 3 , under otherwise identical conditions.

(27) The illumination of a PBMA film doped with $\mathbf{1}$ only does not reveal any fluorescence activation, under otherwise identical conditions.

(28) A movie (Video S1) with the full sequence of 500 frames is available in the Supporting Information.

(29) (a) Yildiz, I.; Impellizzeri, S.; Deniz, E.; McCaughan, B.; Callan, J. F.; Raymo, F. M. J. Am. Chem. Soc. 2011, 133, 871-879. (b) Cusido, J.; Battal, M.; Deniz, E.; Yildiz, I.; Sortino, S.; Raymo, F. M. Chem. Eur. J. 2012, 18, 10399-10407.

(30) Egner, A.; Geisler, C.; von Middendorf, C.; Bock, H.; Wenzel, D.; Medda, R.; Andresen, M.; Stiel, A. C.; Jakobs, S.; Eggeling, C.; et al. Biophys. J. 2007, 93, 3285-3290. 